\title{
Elongation of pulse width as an augmentation strategy in electroconvulsive therapy
}

This article was published in the following Dove Press journal:

Neuropsychiatric Disease and Treatment

23 October 2014

Number of times this article has been viewed

\author{
Hirotsugu Kawashima' \\ Taro Suwa ${ }^{2}$ \\ Toshiya Murai ${ }^{2}$ \\ Ryuichi Yoshioka' \\ 'Department of Psychiatry, \\ Toyooka Hospital, Hyogo, Japan; \\ ${ }^{2}$ Department of Psychiatry, \\ Graduate School of Medicine, \\ Kyoto University, Kyoto, Japan
}

Correspondence: Hirotsugu Kawashima Department of Psychiatry,

Toyooka Hospital, 1094 Tobera,

Toyooka, Hyogo 668-850I, Japan

$\mathrm{Tel}+81796226111$

Fax +8I 796220088

Email kwsm-sig@umin.ac.jp

\begin{abstract}
Inducing adequate therapeutic seizures during electroconvulsive therapy is sometimes difficult, even at the maximum stimulus charge, due to a high seizure threshold. Here, we describe two patients with very poor seizure responses at the maximum charge using conventional stimulus parameters in whom responses were successfully augmented by widening the pulse width at the same or even lower stimulus charge. This strategy could be an additional option for seizure augmentation in clinical practice. The potential clinical utility of stimulus parameter modifications should be further investigated.
\end{abstract}

Keywords: electroconvulsive therapy, pulse frequency, pulse width, stimulus parameter, seizure threshold

\section{Introduction}

Electroconvulsive therapy (ECT) is a highly effective treatment for depressive and other psychiatric disorders. Although it is therapeutically important to induce adequate seizures, it is not uncommon to fail to elicit adequate therapeutic seizures even at the maximum stimulus charge of the device, especially in elderly patients. In such cases, augmentation strategies such as hyperventilation, pretreatment with xanthine, and changing anesthetic agents are often applied. ${ }^{1}$ Although stimulus parameters in ECT including pulse amplitude, pulse shape, pulse width, pulse frequency, and pulse train duration are believed to have unique neurobiological effects, ${ }^{2}$ altering stimulus parameters is rarely discussed as an option for augmentation.

Here, we report two cases whose ictal electroencephalographic (EEG) responses were of very poor quality at the maximum charge with conventional stimulus parameters, but were successfully augmented after widening the pulse width at the same, or even a lower, stimulus charge.

\section{Case I}

A 79-year-old male patient with a history of recurrent depressive episodes experienced a major depressive episode with psychotic features and gradually developed symptoms of catatonia. He was referred from a community hospital, and ECT was quickly started after a pre-ECT workup to exclude any clinical contraindication. His baseline clinical status assessed by global assessment of functioning was ten. ECT was administered twice weekly using a Thymatron System IV (Somatics LLC, Lake Bluff, IL, USA) with bitemporal electrode placement. In the first and second sessions, $50 \%$ (0.5 msec pulse width, $40 \mathrm{~Hz}$ frequency, 7 seconds' duration, and $252 \mathrm{mC}$ total charge) and $80 \%$ (0.5 msec pulse width, $60 \mathrm{~Hz}$ frequency, 7.5 seconds' duration, and $403.2 \mathrm{mC}$ total charge) stimuli by the Low 0.5 preset stimulus program on the device were administered under propofol anesthesia $(0.75 \mathrm{mg} / \mathrm{kg})$. Seizures were elicited, but 
the ictal EEG lacked high-amplitude slow waves, regularity, or post-ictal suppression, and did not result in subsequent clinical improvement. Due to persistent catatonic symptoms, diazepam $10 \mathrm{mg}$ was intravenously administered after the first session, and lorazepam $3 \mathrm{mg}$ was started orally after the second session. Lorazepam was omitted from the night before to the morning of ECT. In and after the third session, theophylline $200 \mathrm{mg}$ was given orally the day before, and flumazenil $0.5 \mathrm{mg}$ was administered at induction of anesthesia. Propofol was switched to ketamine $1 \mathrm{mg} / \mathrm{kg}$, but the $100 \%$ charge $(0.5 \mathrm{msec}$ pulse width, $70 \mathrm{~Hz}$ frequency, 8 seconds' duration, and $504 \mathrm{mC}$ total charge) with the Low 0.5 program also resulted in weak ictal EEG activity (Figure 1A).

In the fourth session, we changed the stimulus parameters as follows: $1 \mathrm{msec}$ pulse width, $70 \mathrm{~Hz}$ frequency, 4 seconds' duration, and $504 \mathrm{mC}$ total charge (DGx stimulus program $100 \%$ ). This stimulus produced an EEG response with highamplitude slow waves and post-ictal suppression (Figure 1B). The patient was then able to answer some questions with effort, but it took him an extremely long time to respond because of his marked psychomotor retardation. His thought was affected by delusion of belittlement (global assessment of functioning 21). After the fourth ECT session, duloxetine $30 \mathrm{mg}$ was started and titrated to $60 \mathrm{mg}$ thereafter. In the fifth session, we extended the pulse width further $(1.5 \mathrm{msec}$ pulse width, $70 \mathrm{~Hz}$ frequency, and 2.7 seconds' duration) at the same charge, which again resulted in weak EEG expression. His psychomotor retardation was exacerbated a few days after the fifth session (global assessment of functioning 15).
In the sixth session, we attempted to adjust the pulse width to $1.25 \mathrm{msec}$ so that the pulse frequency became as low as possible $(30 \mathrm{~Hz})$ at the maximum stimulus charge while keeping the train duration as long as possible ( 7.5 seconds). With this change, both the amplitude and regularity of the ictal EEG response were substantially augmented, and post-ictal suppression was achieved (Figure 1C). The patient showed rapid clinical improvement after this session (global assessment of functioning 40). He received two more treatments with the setting described above, and remission was achieved (global assessment of functioning 70). He experienced no clinically relevant complications, including amnesia. Lorazepam was tapered and discontinued after the last session. His Mini-Mental State Examination score 2 weeks after the last session was 29 points.

\section{Case 2}

An 80-year-old male patient who suffered from recurrent depressive episodes with psychotic features did not respond to multiple antidepressants or antipsychotics. He finally entered a state of stupor and was not able to respond to questions. Because he was a previous ECT responder, ECT was subsequently initiated. His medication included mirtazapine $15 \mathrm{mg}$ and perospirone $8 \mathrm{mg}$ at the initiation of ECT, which was administered twice weekly using a Thymatron System IV device with bitemporal electrode placement. Thiopental $1.5 \mathrm{mg} / \mathrm{kg}$ was used as an anesthetic agent during the course of ECT. Stimuli with 70\% (0.5 msec pulse width, $50 \mathrm{~Hz}$ frequency, 7.8 seconds' duration, and $352.8 \mathrm{mC}$ total charge)

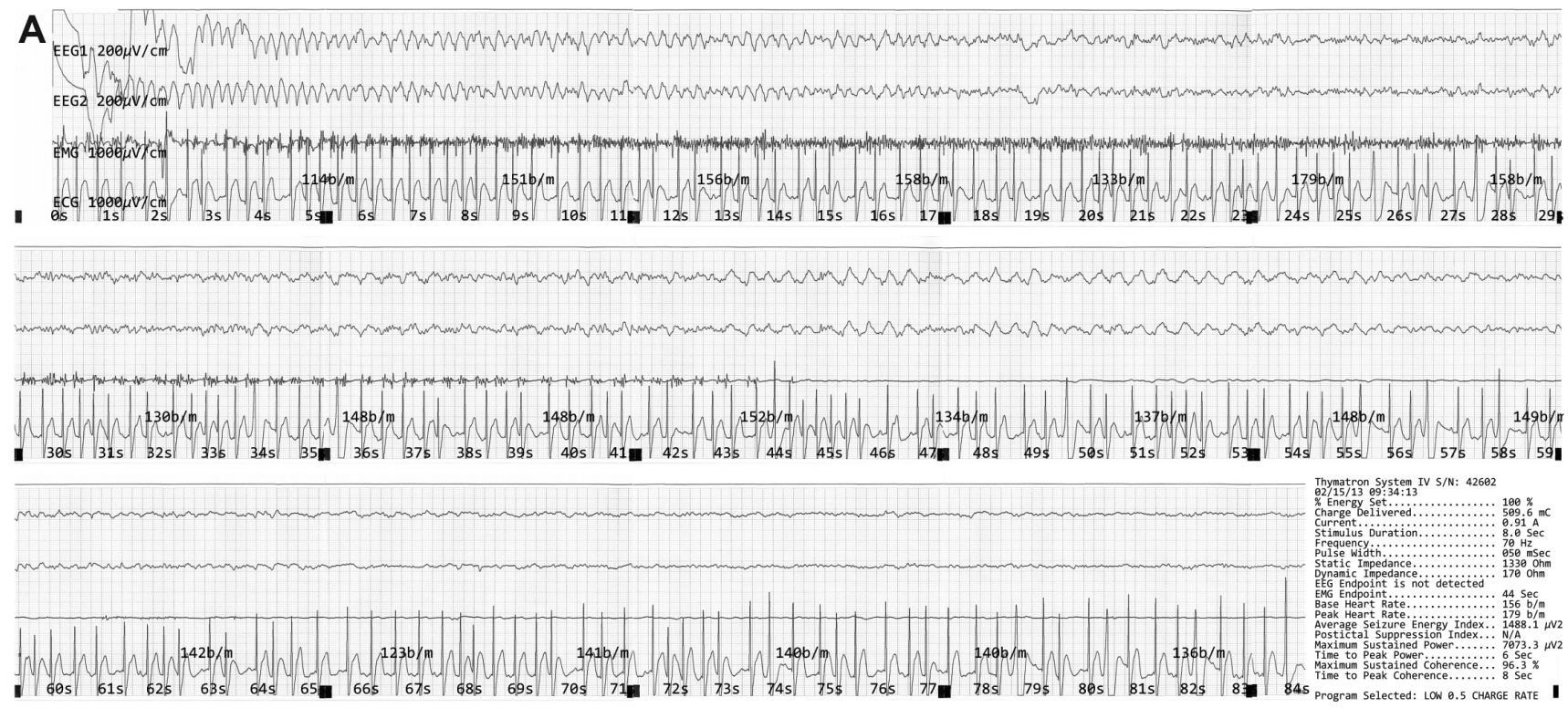

Figure I (Continued) 

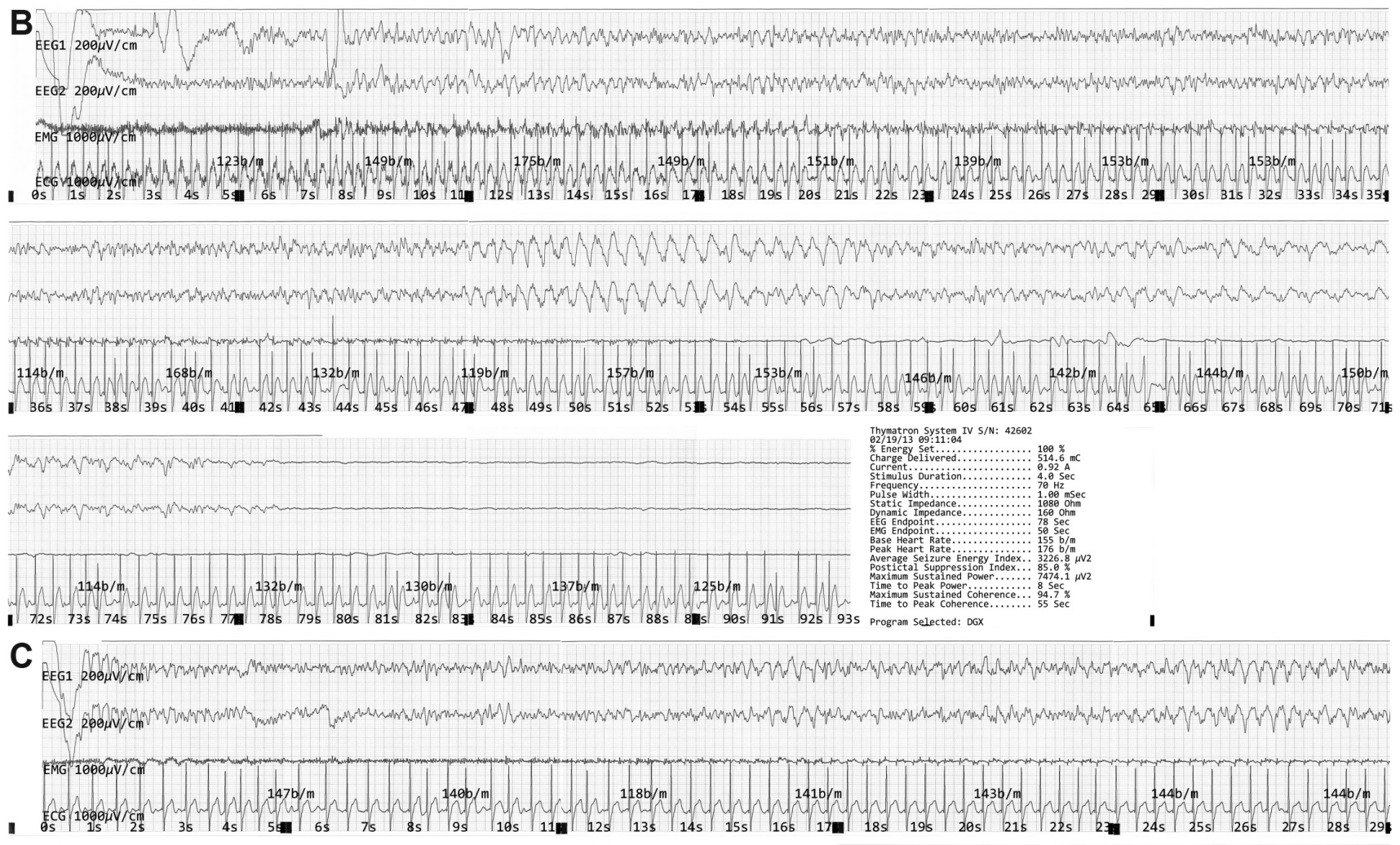

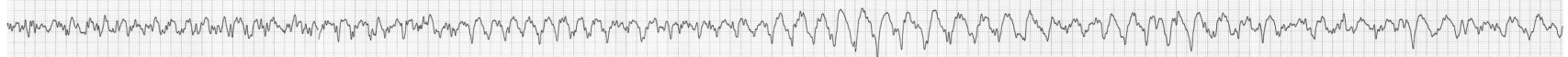

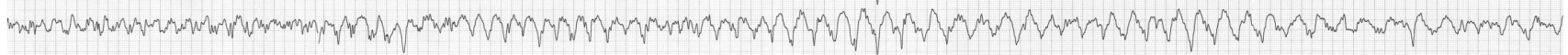

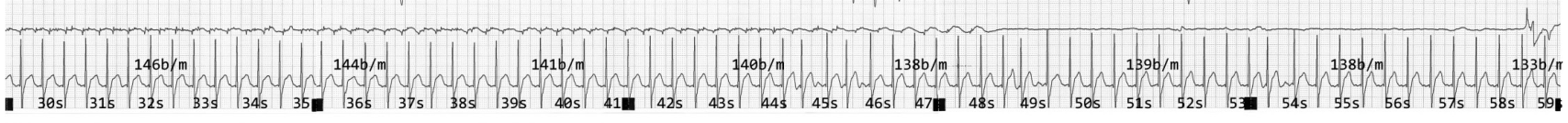

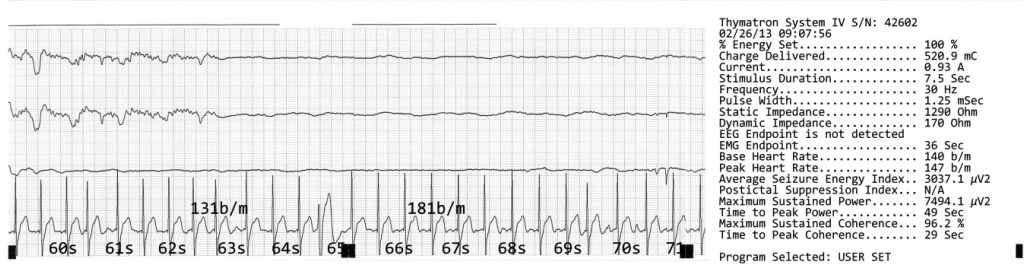

Figure I The ictal EEG in case I.

Notes: (A) Case I, third session. There was no clear progression to the slow-wave phase. The amplitudes of slow waves were low. The peak amplitude was I60 $\mu \mathrm{V}$ (45 seconds). The EMG endpoint was 44 seconds, and the EEG endpoint was obscure. (B) Case I, fourth session. The onset of the slow-wave phase was distinguishable. High-amplitude slow waves were observed from 47 to 58 seconds. The peak amplitude was $360 \mu \mathrm{V}$ (5I seconds). The EMG/EEG endpoints were 54/78 seconds. Post-ictal suppression was achieved, but the transition to flat was gradual. (C) Case I, sixth session. The latency to slow waves was relatively short. High amplitude slow waves were regularly observed. Peak amplitude was $440 \mu \mathrm{V}$ (5I seconds). EMG/EEG endpoints were $48 / 63$ seconds. Post-ictal suppression was achieved, but the transition to flat was still gradual.

Abbreviations: EMG, electromyographic; EEG, electroencephalographic.

in the first session and $100 \%(0.5 \mathrm{msec}$ pulse width, $70 \mathrm{~Hz}$ frequency, 8 seconds' duration, and $504 \mathrm{mC}$ total charge) in the following sessions with the Low 0.5 program could elicit seizures, but EEG expression lacked high-amplitude slow waves, regularity, or post-ictal suppression. Addition of zotepine $50 \mathrm{mg}$ from the fourth session did not improve the ictal waveforms, and no seizure was induced at this setting in the fifth session (Figure 2A).

In the sixth and seventh sessions, the stimulus parameters were changed to the final setting used in case $1(1.25 \mathrm{msec}$ pulse width, $30 \mathrm{~Hz}$ frequency, and 7.5 seconds' duration). Seizures were successfully elicited, but their waveforms were suboptimal (Figure 2B). Mirtazapine and zotepine was withdrawn because they appeared not to contribute to seizure induction or augmentation. As a result, seizure induction failed again in the eighth session.

In the ninth session, the stimulus parameters were altered as follows: $1.5 \mathrm{msec}$ pulse width, $20 \mathrm{~Hz}$ frequency, 7.9 seconds' duration, and $428.4 \mathrm{mC}$ total charge. This change was designed to further lower the pulse frequency and extend the 


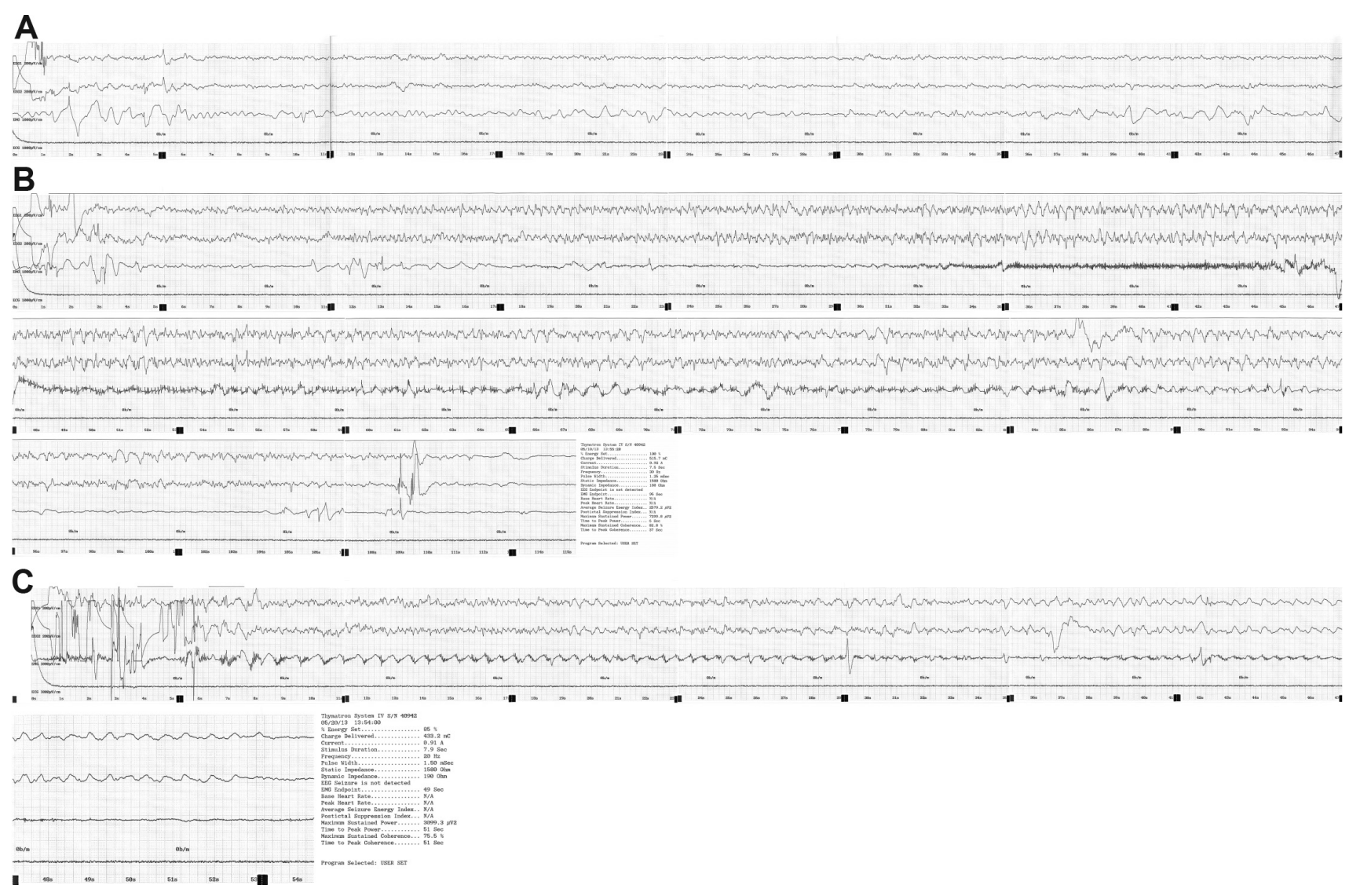

Figure 2 The ictal EEG in case 2.

Notes: (A) Case 2, fifth session. Ictal slow waves were not observed. (B) Case 2, sixth session. Irregular slow waves were observed. The peak amplitude was $320 \mu \mathrm{V}$ (36 seconds). The EMG/EEG endpoints were 94/II 4 seconds. Seizure termination was clear, but suppression was poor. (C) Case 2, ninth session. Irregular slow waves were observed again after the failure in the eighth session. The peak amplitude was $230 \mu \mathrm{V}$ (42 seconds). The EMG/EEG endpoints were $48 / 53$ seconds. Seizure termination was distinguishable, but suppression appeared poor. The post-seizure monitoring time was probably insufficient.

Abbreviations: EMG, electromyographic; EEG, electroencephalographic.

train duration by lengthening the pulse width at the expense of total stimulus charge due to the device's limitations. Seizure induction was successful, even though its waveform was again suboptimal (Figure 2C). Ictal EEG expressions did not change from the tenth session, despite oral premedication with caffeine $0.2 \mathrm{~g}$. The patient achieved a partial remission (Hamilton Depression Rating Scale score 14) without any complications after 13 ECT sessions. Afterward, pharmacotherapy with carbamazepine $300 \mathrm{mg}$ and perospirone $8 \mathrm{mg}$ produced complete remission (Hamilton Depression Rating Scale score 5, Mini-Mental State Examination score 29) 3 weeks after the last session.

\section{Discussion}

Ictal EEG waveforms vary depending on the extent to which the stimulus exceeds the seizure threshold. For example, an adequate suprathreshold (and presumably therapeutic) stimulus tends to produce greater ictal amplitude and regularity, post-ictal suppression, and shorter latency to ictal slow-wave onset. ${ }^{3}$ In the cases presented above, altered ictal EEG waveforms with such features were observed, suggesting that the relative stimulus intensity above seizure threshold can be augmented by modifying stimulus parameters.

Seizure threshold is not determined by a single parameter like total stimulus charge; rather, it is a complex product of numerous parameter combinations. Previous studies on efficiency demonstrated that briefer pulses require less total charge to induce seizures than longer pulses. Swartz and Manly ${ }^{4}$ concluded that a $0.5 \mathrm{msec}$ pulse width is more efficient than a $1 \mathrm{msec}$ pulse width. Sackeim et al ${ }^{5}$ also reported that seizure threshold was approximately three times higher in patients treated with a brief $(1.5 \mathrm{msec})$ pulse compared with an ultrabrief $(0.3 \mathrm{msec})$ pulse stimulus. For this reason, it is quite rational to adopt briefer pulse widths to improve efficiency. However, inducing adequate therapeutic seizures during ECT is sometimes difficult when using a brief pulse width, even at the maximum stimulus charge. This case series demonstrates that, contrary to common 
belief, long pulses might be useful in inducing seizures in specific cases.

The following three findings suggest the possibility of potential benefits of a long pulse width, especially in patients with high seizure thresholds or weak ictal EEG expression. First, Bai et $\mathrm{al}^{6}$ used computer simulation models to show that decreases in pulse width could reduce the sizes of activated brain regions; that is, stimuli with a longer pulse width activate broader regions of the brain. Second, longer stimuli are supposed to have a greater impact on electrophysiological neuronal activity, as briefer pulses preferentially activate the axons, whereas longer pulses also significantly affect the soma and dendrites. ${ }^{7}$ Third, it has been shown that briefer pulse stimuli produce weaker seizure expression. ${ }^{2,8}$ Collectively, the evidence indicates that longer pulse stimuli probably activate broader regions of the brain, have great electrophysiological impact on neurons, and produce more intense ictal EEG waveforms. Therefore, elongation of pulse width could be a useful strategy when adequate seizures cannot be induced at the maximum stimulus charge and duration.

Indeed, in our first case, the fourth treatment with doubled ( $1 \mathrm{msec}$ ) pulse width and halved (4 seconds) duration produced a conspicuous ictal EEG response although the charge rate was increased (charge rate is defined as the stimulus charge/s, and a lower charge rate is commonly believed to be advantageous for seizure induction). ${ }^{6-11}$ Inomata et $\mathrm{al}^{9}$ also reported a case in which seizures were induced with $1 \mathrm{msec}$ and $1.5 \mathrm{msec}$ pulse widths after failure with $0.5 \mathrm{msec}$ and $0.25 \mathrm{msec}$ pulses widths at the maximum stimulus charge. Notably, the charge rates were higher at the same or even reduced stimulus charge in their case. Given the disadvantages of increased charge rates and reduced total stimulus charge, long pulses thus seem to play a functional role.

There is methodological difficulty in examining and determining the effect of a single stimulus parameter because the parameters influence each other. In both cases described here, pulse width, pulse frequency, and pulse train duration were adjusted, making it impossible to clearly determine which of these individual parameters actually improved the efficiency. Nevertheless, the fact that longer pulse stimuli produced improvement of ictal EEG waveforms in the condition where pulse frequency and pulse train duration were shifted in an unfavorable way indicates that pulse width elongation can be a beneficial augmentation strategy.

Another useful strategy might be to decrease charge rates by lowering pulse frequencies and keeping pulse train durations as long as possible, as in the sixth session of case 1 . This is in accordance with previous reports. ${ }^{10-14}$ For example, Ravishankar et $\mathrm{al}^{15}$ reported a case of successful seizure induction by increasing stimulus duration and decreasing pulse frequency in a patient in whom seizure induction was not possible with conventional stimulus parameters at the same charge. This strategy seemed effective even at the reduced total stimulus charge, as seen in the ninth session of case 2 , where both elongation of pulse width and lowering of charge rate were applied.

It should be noted that longer pulses may have a greater risk of memory or cognitive impairment. Sine wave stimulation produces more impairment than brief pulse stimulation. ${ }^{16}$ Recent trials comparing ultrabrief and brief pulse ECT ${ }^{5,17-19}$ have demonstrated reduced cognitive disturbance with briefer pulse width. Although comparisons between brief pulse widths are scarce, the same conclusion can be speculatively drawn from these findings.

\section{Conclusion}

Lengthening pulse width should be sparingly applied because it may increase the risk of memory impairment. Nonetheless, it can be justified under conditions where adequate seizures cannot be induced at the maximum stimulus charge and duration. When applying this strategy, it should be considered to reduce the charge rate by lowering the pulse frequency and keeping the pulse train duration as long as possible. The proposed usefulness of our strategy requires additional validation in larger numbers of patients. The effects of various stimulus parameters have not been thoroughly explored as yet, and should be investigated in more detail.

\section{Disclosure}

The authors report no conflicts of interest in this work.

\section{References}

1. Loo C, Simpson B, MacPherson R. Augmentation strategies in electroconvulsive therapy. J ECT. 2010;26(3):202-207.

2. Peterchev AV, Rosa MA, Deng ZD, Prudic J, Lisanby SH. Electroconvulsive therapy stimulus parameters: rethinking dosage. JECT. 2010;26(3): 159-174.

3. Krystal AD, Weiner RD, Coffey CE. The ictal EEG as a marker of adequate stimulus intensity with unilateral ECT. J Neuropsychiatry Clin Neurosci. 1995;7(3):295-303.

4. Swartz CM, Manly DT. Efficiency of the stimulus characteristics of ECT Am J Psychiatry. 2000;157(9):1504-1506.

5. Sackeim HA, Prudic J, Nobler MS, et al. Effects of pulse width and electrode placement on the efficacy and cognitive effects of electroconvulsive therapy. Brain Stimul. 2008;1(2):71-83.

6. Bai S, Loo C, Dokos S. Effects of electroconvulsive therapy stimulus pulse width and amplitude computed with an anatomicallyrealistic head model. Conf Proc IEEE Eng Med Biol Soc. 2012 2559-2562. 
7. Nowak LG, Bullier J. Axons, but not cell bodies, are activated by electrical stimulation in cortical gray matter. I. Evidence from chronaxie measurements. Exp Brain Res. 1998;118(4):477-488.

8. Mayur P, Harris A, Rennie C, Byth K. Comparison of ictal electroencephalogram between ultrabrief- and brief-pulse right unilateral electroconvulsive therapy: a multitaper jackknife analysis. JECT. 2012; 28(4):229-233.

9. Inomata $\mathrm{H}$, Harima $\mathrm{H}$, Itokawa $\mathrm{M}$. A case of schizophrenia successfully treated by m-ECT using "long" brief pulse. International Journal of Case Reports and Images. 2012;3(7):30-34.

10. Swartz CM, Larson G. ECT stimulus duration and its efficacy. Ann Clin Psychiatry. 1989;1(3):147-152.

11. Rasmussen KG, Zorumski CF, Jarvis MR. Possible impact of stimulus duration on seizure threshold in ECT. Convuls Ther. 1994;10(2):177-180.

12. Devanand DP, Lisanby SH, Nobler MS, Sackeim HA. The relative efficiency of altering pulse frequency or train duration when determining seizure threshold. JECT. 1998;14(4):227-235.

13. Girish K, Gangadhar BN, Janakiramaiah N, Lalla RK. Seizure threshold in ECT: effect of stimulus pulse frequency. J ECT. 2003;19(3): $133-135$.
14. Kotresh S, Girish K, Janakiramaiah N, Rao GU, Gangadhar BN. Effect of ECT stimulus parameters on seizure physiology and outcome. JECT. 2004;20(1):10-12.

15. Ravishankar V, Narayanaswamy JC, Thirthalli J, Reddy YC, Gangadhar BN. Altering pulse frequency to enhance stimulus efficiency during electroconvulsive therapy. J ECT. 2013;29(1):e14-e15.

16. Fraser LM, O'Carroll RE, Ebmeier KP. The effect of electroconvulsive therapy on autobiographical memory: a systematic review. J ECT. 2008;24(1):10-17.

17. Loo CK, Sainsbury K, Sheehan P, Lyndon B. A comparison of RUL ultrabrief pulse $(0.3 \mathrm{~ms})$ ECT and standard RUL ECT. Int J Neuropsychopharmacol. 2008;11(7):883-890.

18. Verwijk E, Comijs HC, Kok RM, Spaans HP, Stek ML, Scherder EJ. Neurocognitive effects after brief pulse and ultrabrief pulse unilateral electroconvulsive therapy for major depression: a review. J Affect Disord. 2012;140(3):233-243.

19. Mayur P, Byth K, Harris A. Autobiographical and subjective memory with right unilateral high-dose 0.3 -millisecond ultrabrief-pulse and 1-millisecond brief-pulse electroconvulsive therapy: a double-blind, randomized controlled trial. J ECT. 2013;29(4):277-282.

\section{Dovepress}

\section{Publish your work in this journal}

Neuropsychiatric Disease and Treatment is an international, peerreviewed journal of clinical therapeutics and pharmacology focusing on concise rapid reporting of clinical or pre-clinical studies on a range of neuropsychiatric and neurological disorders. This journal is indexed on PubMed Central, the 'PsycINFO' database and CAS, and is the official journal of The International Neuropsychiatric Association (INA). The manuscript management system is completely online and includes a very quick and fair peer-review system, which is all easy to use. Visit http://www.dovepress.com/testimonials.php to read real quotes from published authors. 